\title{
The Effects of Action Learning on Problem-solving Process, Team Efficacy, and Team Outcome of Nursing Students
}

\author{
Jung-Ha Park1)
}

\begin{abstract}
The present study applied a single-project-based problem-finding action to clinical-nursing practice to identify changes in the problem-solving process, team efficacy, and team outcome of nursing students. The data were collected between October 30 and November 24, 2017. The research subjects were 57 fourth-year nursing students attending one nursing school in B Metropolitan City. A problem-finding program of action learning was carried out over 2 weeks; the collected data were analyzed using the SPSS Win 24 Program, with descriptive statistics used for general characteristics and a repeated-measures ANOVA for research variables. The study achieved significant results in the following areas: the problem-solving process, team efficiency, and team outcomes. In sub-areas of the problem-solving process, the study achieved significant results in relation to problem finding, defining the problem, devising a solution to the problem, executing a solution to the problem, and reviewing the problem-solving process. These results indicate that further research is needed on the development and applicability of action-learning programs designed to increase the competency of nursing students in clinical-nursing practice.
\end{abstract}

Keywords: Action Learning, Problem-solving Process, Team Efficacy, Team Outcome, Nursing Students

\section{Introduction}

The Korean Accreditation Board of Nursing Education manages and supports the quality of nursing education to ensure that the curriculum used in nursing studies can produce competent nurses[1]. In the field of nursing, competency involves the ability to effectively handle the general requirements of the nursing role, perform a role in a particular nursing administration, and combine and apply techniques, knowledge, and judgement[2]. More than 1,000 hours of clinical practice must be completed during the nursing-education process[1]. Clinical practice is essential, ensuring that nursing students learn to directly apply theoretical knowledge in a practical environment, while also achieving professional socialization by acquiring the techniques and attitudes needed to solve problems in practice[3][4].

Received (May 6, 2019), Review Result (1st: June 1, 2019, 2nd: August 8, 2019), Accepted (September 10, 2019)

1) (Assitant professor) 47011 Dept. Nursing Science, Dongseo University, Jurye-ro, Sasang-gu, Busan, Korea email: suha2002@gdsu.dongseo.ac.kr 
Nursing educators must continuously develop and improve educational methods and strategies to provide nursing students with the experience of solving patient problems effectively in a clinical-practice setting. In Korea, the learner-centered educational method of action learning is currently being used in practicum classes and the fields of Nursing Management, Adult Nursing, Mental Health Nursing, Maternal Nursing, and Geriatric Nursing [5-8].

The main characteristic that sets action learning apart from other educational programs is the fact that it deals with actual problems[9]. In the action learning education method, learners form small groups and, along with the facilitator, solve the task until a set time; simultaneously, through knowledge acquisition, questioning, feedback, and reflection they learn aspects of task content and task performance[10]. Learners form small groups with a supervisor to resolve a task within a defined time, while simultaneously learning about the content of the task and the process of performing it by acquiring knowledge, asking questions, receiving feedback, and reviewing the process[10]. Through action learning, students gain expertise and learn to solve problems. They also learn in groups, build teams, develop leadership skills and acquire experience[9]. For all of these reasons, action learning is often used in other countries to teach nursing counselors[11], nursing-home managers[12], new nurses and midwives[13], more experienced nurses[14], and nursing students and mentors[15] in clinical settings.

There is a method of action learning in which individuals perform one task as a team. In such single-project programs, people are grouped into teams and team members handle one common task[9]; discussion through team learning has a positive effect on members, strengthening their ability to solve problems[16-18]. Not only is action learning an effective method of solving problems, it is also a driving force that creates strong teams, thereby promoting team learning. Individual members are able to practice effective team-learning techniques within teams[9].

Team efficiency is an overall evaluation of the team members' ability to carry out a task[19]. In addition to enhancing activities performed at the team level, team efficiency also modifies and combines the efforts of individual team members[20]. As the outcome of a team formed within an organization is linked to the individual strengths and actions of its members, working with team members as individuals produces a valuable synergic effect. Team outcomes are thus more significant than individual performances[21].

Recently, action learning is also applied to online tutoring programs[22]. As a facilitator, a learning coach helps to study aspects of the task content and problem-solving process by questioning, feedback, and reflection on the entire process when carrying out team tasks[10]. 
For these reasons, introducing a single-project program of action learning to nursing students during clinical practice is likely to enhance the problem-solving process, while also improving team efficacy and team outcomes.

Two types of problems occur during the action-learning problem-solving process: a) exploratory problems that involve making or finding new opportunities; and b) hidden problems that already exist in the setting but must be found and solved[9]. Nursing Education Evaluation Institute manages the quality of clinical practice education[23] and within the Korean clinical-practice setting, the second "problem-finding" action-learning approach is considered more appropriate, reflecting the types of problems that nursing students must learn to identify in clinical settings.

The present study has therefore introduced nursing students to a problem-finding action-learning program during clinical-nursing practice, enabling them to improve their problem-solving, team efficacy, and team outcomes during the process of searching for, identifying, and solving nursing-management problems at a clinical site.

\subsection{The Purpose of this Research}

The present study has applied a single-project-based problem-finding program of action learning to clinical-nursing practice in order to identify the nursing students' changes in problem-solving, team efficiency, and team outcomes, as well as to establish basic data for popularizing the action-learning approach.

\section{Research Methods}

\subsection{The Research Design}

A single-group pre-test/post-test design has been used to compare the effect of conducting a single-project-based action-learning program within the clinical-nursing practice curriculum on students' ability to solve problems in teams; the design has also assessed the students' team efficiency and team outcomes.

\subsection{The Research Subjects and Data Collection}

The participants were fourth-year nursing students enrolled in a clinical-nursing practice course at a single university in K City. The researcher explained the purpose and method of this 
research, the benefits and potential drawbacks of participating, and the fact that privacy was guaranteed, while participants were free to withdraw at any time. The participants voluntarily gave their consent to participate in this study. Data were collected between October 30 and November 24, 2017. After the pre-test, a post-test was conducted every week during the two-week intervention. Of the 63 subjects, 6 did not complete the surveys and were excluded, leaving 57 subjects whose data were used in the final analyses. The necessary number of subjects was calculated using the $G^{*}$ power 3.1.7 program:[24] effect size $=.25$, significance level $=.05$, and statistical power $=.95$; this showed that at least 36 subjects were needed. The sample size of 57 was therefore found to be sufficient.

\subsection{Research Tools}

\subsubsection{The Problem-solving Process}

The problem-solving process used a tool developed by Lee et al.[25] and revised and supplemented by Woo[26]. The tool consisted of 25 items: 5 in each of 5 sub-areas of "problem finding," "defining the problem," "devising a solution to the problem," "executing a solution to the problem," and "reviewing the problem-solving process." Each item was measured using a 5-point Likert scale, with responses ranging from 1 (Not at all) to 5 (Almost always). A higher score indicated a higher level of problem-solving. The Cronbach's a was .89 in Woo[26]; in the present study, it was .840 before, .914 during, and .912 after the problem-solving process.

\subsubsection{Team Efficacy}

To assess team efficacy, based on research by Chen, Gully, and Eden[27] and Kim[28], we used a tool developed by Han[29]. This tool consisted of 6 items. Each item was measured using a 5-point Likert scale, with responses ranging from 1 (Strongly disagree) to 5 (Strongly agree). A higher score indicated a higher level of team efficacy. The Cronbach's a was .904 in Han[29]; in the present study, it was .902 before, .970 during, and .974 after the action-learning program.

\subsubsection{Team Outcome}

To assess the team outcome, based on Henderson and Lee[30], Shin[31], and Yim[32], we used a tool developed by Son[33], This tool consisted of 4 items. Each item was measured using a 5-point Likert scale, with responses ranging from 1 (Strongly disagree) to 5 (Strongly agree). A higher score indicated a better team outcome. The Cronbach's a was .880 in Son[33]; in the present study, it was .902 before, .906 during, and .892 after the intervention. 


\subsection{Data Analysis Method}

Collected data were analyzed using the SPSS WIN 24 Program. The subjects' general characteristics were analyzed using descriptive statistics; a repeated-measures ANOVA was used to test differences in the problem-solving process, team efficacy, and team outcome before, during, and after the action-learning program.

\section{Result}

A single-project learning method, in which an entire team would solve a single problem, was selected as the task. Before the practice began, participants were given an orientation session on problem-finding action learning. The program progressed through four stages: problem finding, analyzing the cause of the problem, selecting and developing a solution to the problem, and executing and evaluating the solution, as shown in Figure 1[9]. In the problem-finding stage, the teams used decision-making grids to select a task associated with a high-priority problem in secondary and tertiary hospital wards; the current status of the problem was analyzed in more detail and broken down. During the analysis stage, a hypothesis about the root cause of the core problem was established and tested. The cause was then identified and verified. To select and develop a solution, the participants chose an optimal problem-solving method by considering all available hospital resources. They then established detailed execution plans. During the execution and evaluation stage, the subjects carried out the completed plans, evaluated the results, and obtained feedback. Overall, the 10 teams carried out the following tasks: those based at a secondary general hospital worked on "producing location maps for patients and families," "improving the infection-control environment and providing materials to re-educate families and caregivers," "managing patient bracelets using videos," and "searching for a solution to reduce noise." Those based at a tertiary university hospital worked on "managing the environment around the radiator," "improving procedures for dealing with medical and contaminated waste," "effectively managing hospital infections," "reducing patient stress using humor," "applying and evaluating halter monitor usage guidelines," and "developing educational data to provide information to patients efficiently after a coronary angiography."

There were 7 male and 50 female research subjects, with a mean age of 23 years. Differences in the teams' problem-solving processes, efficacy, and outcomes before, during, and after the application of the action-learning program are shown in Table 1. The subjects' ability to solve problems improved significantly from $3.64 \pm 0.35$ before the action-learning program to $3.81 \pm 0.45$ 


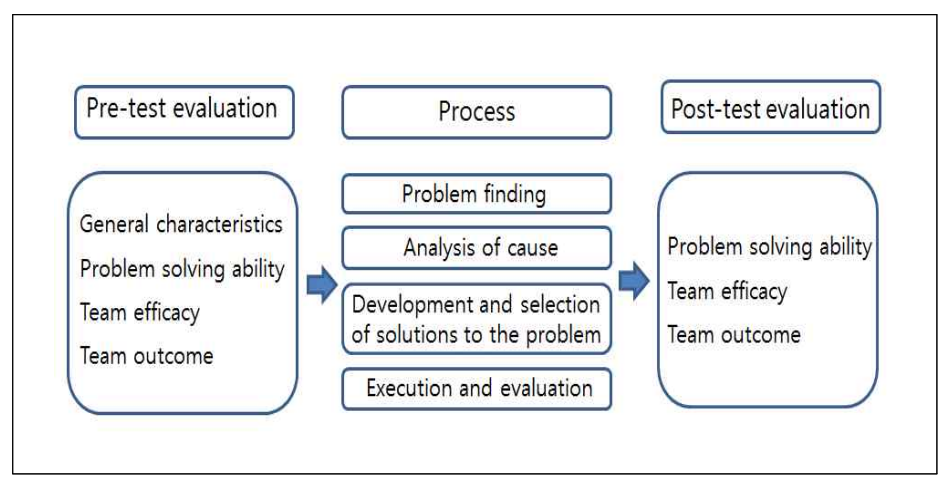

[Fig. 1] The Action-learning Process

one week after the program, and $3.96 \pm 039$ two weeks later. Among the sub-areas of the problem-solving process, problem finding significantly increased, from $3.77 \pm 0.45$ before the program to $4.02 \pm 0.51$ one week after the program, and $4.13 \pm 0.40$ two weeks later. The participants' ability to define problems significantly improved from $3.47 \pm 0.52$ before the program to $3.76 \pm 0.55$ one week after the program, and $3.96 \pm 0.51$ two weeks later. However, the participants' ability to devise a solution to the problem decreased significantly, from $4.29 \pm 0.45$ to $4.01 \pm 0.58$ and $4.15 \pm 0.51$, respectively. Their ability to execute a solution to the problem significantly increased from $3.23 \pm 0.39$ to $3.45 \pm 0.40$ and $3.56 \pm 0.43$, while their ability to review the problem-solving process significantly increased from $3.42 \pm 0.55$ to $3.79 \pm 0.65$ and $3.99 \pm 0.54$. Team efficacy significantly increased from $3.85 \pm 0.61$ before the action learning to $4.30 \pm 0.82$ one week later and $4.44 \pm 0.74$ two weeks later. Team outcomes also improved significantly, from $4.06 \pm 0.59$ before the application to $4.40 \pm 0.58$ and $4.56 \pm 0.53$, respectively.

[Table 1] Changes in the Problem-solving Process, Team Efficacy, and Team Outcomes $(\mathrm{N}=57)$

\begin{tabular}{|l|c|c|c|c|c|}
\hline \multirow{2}{*}{\multicolumn{1}{|c|}{ Variable }} & \multicolumn{3}{c|}{ Mean \pm SD } & \multirow{2}{*}{ F } & $\mathrm{p}$ \\
\cline { 2 - 4 } & Pre-test & Mid-test & Post-test & & \\
\hline Problem-solving ability & $3.64 \pm 0.35$ & $3.81 \pm 0.45$ & $3.96 \pm 039$ & 17.93 & $<.001$ \\
Problem finding & $3.77 \pm 0.45$ & $4.02 \pm 0.51$ & $4.13 \pm 0.40$ & 13.29 & $<.001$ \\
Defining the problem & $3.47 \pm 0.52$ & $3.76 \pm 0.55$ & $3.96 \pm 0.51$ & 21.50 & $<.001$ \\
Devising a solution to the problem & $4.29 \pm 0.45$ & $4.01 \pm 0.58$ & $4.15 \pm 0.51$ & 5.27 & $<.001$ \\
Executing a solution to the problem & $3.23 \pm 0.39$ & $3.45 \pm 0.40$ & $3.56 \pm 0.43$ & 11.61 & $<.001$ \\
Reviewing the problem-solving process & $3.42 \pm 0.55$ & $3.79 \pm 0.65$ & $3.99 \pm 0.54$ & 24.04 & $<.001$ \\
Team efficacy & $3.85 \pm 0.61$ & $4.30 \pm 0.82$ & $4.44 \pm 0.74$ & 15.29 & $<.001$ \\
Team outcome & $4.06 \pm 0.59$ & $4.40 \pm 0.58$ & $4.56 \pm 0.53$ & 15.49 & $<.001$ \\
\hline
\end{tabular}




\section{Conclusion}

The present study carried out a single-project-based problem-finding action-learning program as a clinical-nursing practice intervention for fourth-year nursing students. This study show that a single-project-based problem-finding program of action learning can enhance the problem-solving process, team efficacy, and team outcomes of nursing students.

The results of this study suggest that follow-up studies using different groups or an increased sample size should be carried out to test the applicability of this program to nursing-management practice education. It will also be necessary to conduct continuous interventions and to replicate research on factors that have a long-term impact on the problem-solving process, team efficacy, and team outcomes after the action-learning process.

\section{Acknowledgement}

This work was supported by Dongseo University, "Dongseo Cluster Project" Research Fund of 2019(DSU-20190011).

\section{References}

[1] http://www.kabone.or.kr/kabon02/index04.php, Feb 19 (2004).

[2] B. Campbell and G. Mackay, Continuing competence: An Ontario nursing regulatory program that supports nurses and employers, Nursing Administration Quarterly, (2001), Vol.25, No.2, pp.22-30, DOI: 10.1097/00006216-200101000-00006.

[3] M. H. Cho and I. S. Kwon, A study on the clinical practice experiences on nursing activities of nursing students, The Journal of Korean Academic Society of Nursing Education, (2007), Vol.13, No.2, pp.143-154, UCI: G704-001961.2007.13.2.009

[4] E. E. B. Patterson, L. Boyd and G. Mnatzaganian, The impact of undergraduate clinical teaching models on the perceptions of work-readiness among new graduate nurses: A cross sectional study, Nurse Education Today, (2017), Vol.55, pp.101-106, DOI: 10.1016/j.nedt.2017.05.010

[5] K. S. Jang and S. J. Park, Effects of action learning approaches on learning outcomes in nursing management courses, Journal of Korean Academy of Nursing Administration, (2012), Vol.18, No.4, pp.442-451, DOI: 10.11111/jkana.2012.18.4.442

[6] J. H. Kim and M. K. Park, Comparative study on self-leadership, team efficacy, problem-solving process and task satisfaction of nursing students in response to clinical training, The Journal of Korean Academic 
Society of Nursing Education, (2014), Vol.20, No.4, pp.482-490, DOI: 10.5977/jkasne.2014.20.4.482

[7] S. M. Kwon, M. S. Kwon and J. Y. Park, The effect of a gerontological clinical-nursing practice course using action learning on undergraduate nursing students, Journal of Korea Academia-Industrial Cooperation Society, (2016), Vol.17, No.5, pp.421-427, DOI: 10.5762/KAIS.2016.17.5.421

[8] M. R. Han, Development and evaluation a critical care practicum program for nursing students based on action learning, Yonsei University, Doctoral Thesis, (2018)

[9] K. S. Jang, K. H. Jung, M. Hak, H. Y. Park and Y. Choi, Action Learning and Creative Problem Solving for Nursing Leadership, Hyunmoon, (2016)

[10] H. C. Bong, Do action learning for success, Hangseong B Wave, (2011)

[11] S. Young, E. Nixon, D. Hinge, J. McFadyen, V. Wright, P. Lambert, C. Pilkington and C. Newsome, Action learning: a tool for the development of skills for nurse consultants?, Journal of Nursing Management, (2010), Vol.18, No.1, pp.105-110, DOI: 10.1111/j.1365-2834.2009.01059.x

[12] A. Hewison, F. Badger, T. Swani, Leading end-of-life care: an action learning set approach in nursing homes, International Journal of Palliative Nursing, (2011), Vol.17, No.3, pp.135-141, DOI: 10.12968/ijpn.2011.17.3.135

[13] A. I. Machin, and P. Person, Action learning sets in a nursing and midwifery practice learning context: a realistic evaluation, Nurse Education in Practice, (2014), Vol.14, No.4, pp.410-416, DOI: 10.1016/j.nepr.2014.01.007

[14] R. Diana, C. Hazel and A. Helen, Developing leadership through action learning, Nursing Standard, (2002), Vol.16, No.29, pp.37-39, DOI: 10.7748/ns2002.04.16.29.37.c3177

[15] N. Brooks and A. Moriarty, Development of a practice learning team in the clinical setting, Nursing Standard, (2006), Vol.20, No.33, pp.41-44, DOI: 10.7748/ns2006.04.20.33.41.c4133

[16] M. Bering, A personal journey into leadership, Nursing Management, (2006), Vol.13, No.4, pp.20-25, DOI: 10.7748/nm.13.4.20.s13

[17] R. Diana, C. Hazel and A. Helen, Developing leadership through action learning, Nursing Standard, (2002), Vol.16, No.29, pp.37-39, DOI: 10.7748/ns2002.04.16.29.37.c3177

[18] J. Raelin, Does action learning promote collaborative leadership?, Academy of Management, Learning \& Education, (2006), Vol.5, No.2, pp.152-168, DOI: https://doi.org/10.5465/amle.2006.21253780

[19] C. B. Gibson, Do they do what they believe they can? Group efficacy and group effectiveness across tasks and cultures, The Academy of Management Journal, (1999), Vol.42, No.2, pp.138-152, DOI: https://doi.org/10.2307/257089

[20] C. B. Gibson, A. E. Randel, and A. E. Earley, Understanding group-efficacy: An empirical test of multiple assessment methods, Group \& Organization Management, (2000), Vol.25, No.1, pp.67-97, DOI: DOI:10.1177/1059601100251005

[21] Y. K. Jung and K. M. Lee, An Empirical Study on the Relationships between Transformational Leadership, Collective Efficacy, and Team Effectiveness, Korean Public Administration Quarterly, (2007), Vol.19, No.4, pp.1053-1074, UCI: G704-000253.2007.19.4.014 
[22] H. J. Lee, Action Learning-based Online Tutoring Program Guidelines Exploration: Focusing on B Cyber University, Pusan National University, Master's Thesis, (2016)

[23] A report on evaluation of nursing school, Korean Accreditation Board of Nursing Education, (2017)

[24] F. Faul, E. Erdfelder, A. G. Lang and A. Buchner, G*POWER 3: A flexible statistical power analysis program for the social, behavioral, and biomedical sciences, Behavior Research Methods, (2007), Vol.39, No.2, pp.175-191, DOI: https://doi.org/10.3758/BF03193146

[25] S. J. Lee, Y. K. Jang, H. N. Lee, K. Y. Park, A Study on the Development of Lifelong Learning Tools: Communication Skills Focusing on problem solving ability, self-directed learning ability, Korean Educational Development Institute, (2003)

[26] O. H. Wo, The effect of problem-based learning on the problem-solving process according to learners' Metacognitive level, Korean National University Education, Master's Thesis, (2000)

[27] G. Chen, S. M. Gully and D. Eden, Validation of a new general self-efficacy scale, Organizational Research Methods, (2001), Vol.4, No.1, pp.62-83, DOI: https://doi.org/10.1177/109442810141004

[28] D. S. Kim and M. J. Kim, The Effect of Team Learning Behavior and Shared Mental Models on Team Performance- Focused on the Moderating Effect of Team Efficacy, Global Business Administration Review, (2014), Vol.11, No.4, pp.347-377, DOI: 10.17092/jibr.2014.11.4.347

[29] J. W. Han, The Relationship of Shared Mental Model, Transactive Memory System, Team Efficacy and Team Performance, Gachon University, Doctoral Thesis, (2016)

[30] J. C. Henderson, and S. C. Lee, Managing I/S design teams: A control theories perspective, Management Science, (1992), Vol.38, No.6, pp.757-777.

[31] J. K. Shin, A study on predictive variables collective efficacy and its effect on performance, Kookmin University, Doctoral Thesis, (1999)

[32] H. J. Im, The Integrated Model of Knowledge Worker Team Effectiveness: The Role of Shared Cognition, Ewha Woman's University, Doctoral Thesis, (2005)

[33] J. M. Son, The Effect of Shared Knowledge of Team Performance among Team Members-Focused on the mediating effect of TMS, Gachon University, Master's Thesis, (2016) 